\title{
Energy balance dynamics during short-term High-Intensity Functional Training
}

\begin{tabular}{|r|l|}
\hline Journal: & Applied Physiology, Nutrition, and Metabolism \\
\hline Manuscript ID & apnm-2018-0311.R1 \\
\hline Manuscript Type: & Article \\
\hline Author: & 24-Jun-2018 \\
\hline $\begin{array}{r}\text { Complete List of Authors: } \\
\text { Keyword: }\end{array}$ & $\begin{array}{l}\text { Kinesiology } \\
\text { Palumbo, Elyse; California State University San Marcos, } \\
\text { Kinesiology }\end{array}$ \\
\hline $\begin{array}{r}\text { Is the invited manuscript } \\
\text { for consideration in a } \\
\text { Special Issue? : }\end{array}$ & Not applicable (regular submission) \\
\hline \hline
\end{tabular}




\title{
Energy balance dynamics during short-term High-Intensity Functional Training
}

\author{
Matthew M. Schubert ${ }^{1,2}$ and Elyse A. Palumbo ${ }^{1}$ \\ ${ }^{1}$ Department of Kinesiology \\ California State University, San Marcos \\ 333 S. Twin Oaks Valley Road \\ San Marcos, CA, USA 92096-0001 \\ ${ }^{2}$ To whom correspondence may be addressed \\ mschubert@csusm.edu \\ Phone: (760)750-7362 \\ Fax: (760)750-3237 \\ ORCID: 0000-0002-0994-8805
}

Running head: Energy balance during functional training 


\begin{abstract}
CrossFit $^{\mathrm{TM}}(\mathrm{CF})$ is a form of high-intensity functional training (HIFT) that focuses on training across the entire spectrum of physical fitness. CF has been shown to improve a number of indicators of health but little information assessing energy balance exists. The purpose of the present study was to investigate energy balance during 1 week of CF training. Men and women ( $\mathrm{n}=21$, mean age and BMI: $43.5 \pm 8.4 \mathrm{y} ; 27.8 \pm 4.9 \mathrm{~kg} \cdot \mathrm{m}^{-2}$ ), with $\geq 3$ months CF experience, had body composition assessed via air displacement plethysmography before and after 1 week of CF training. Participants wore ActiHeart monitors to assess total energy expenditure (TEE), activity energy expenditure (AEE), and CF energy expenditure (CF EE). Energy intake was assessed from TEE and $\Delta$ body composition. CF EE averaged $605 \pm 219 \mathrm{kcal}$ per $72 \pm 10 \mathrm{~min}$ session. Weekly CF EE was $2723 \pm 986$ kcal. Participants were in an energy deficit (TEE: 3674 $\left.\pm 855 \mathrm{kcal} \cdot \mathrm{d}^{-1} ; \mathrm{EI}: 3167 \pm 1401 \mathrm{kcal} \cdot \mathrm{d}^{-1}\right)$. Results of the present study indicate that CF training can account for a significant portion of daily activity energy expenditure. The weekly expenditure is within levels shown to induce clinically meaningful weight loss in overweight/obese populations.
\end{abstract}

Key words: Functional training; weight management; energy balance 


\section{Introduction}

The health burden of physical inactivity in the United States is considerable, with only $\sim 5 \%$ of Americans meeting physical activity guidelines of 30 minutes of moderate-vigorous activity per day (Troiano et al. 2008). High-intensity functional training (HIFT) and high-intensity interval training (HIIT) have been promoted as time-efficient stimuli compared to traditional continuous endurance training (Gibala and Hawley 2017). CrossFit ${ }^{\mathrm{TM}}(\mathrm{CF})$ was established in 1996 as a means to prepare an athlete to successfully perform varied and randomized physical tasks. This philosophy leads to training across the physical fitness spectrum, with strength, power, and endurance incorporated into single movements or exercise sessions (2017). Typically, endurance exercise (running, rowing, cycling, etc.) and resistance training (body weight exercises, Olympic lifts, power lifts, plyometrics, etc.) are completed in a single exercise class. Literature has indicated that $\mathrm{CF}$ is effective for improving body composition, aerobic capacity $\left(\mathrm{VO}_{2} \mathrm{max}\right)$, anaerobic capacity, muscular strength and endurance, flexibility, and power (Sobrero et al. 2015; Zagdsuren et al. 2015; Serafini et al. 2016; Drake et al. 2017). Moreover, the CF industry has grown exponentially, with $\sim 13,000$ worldwide gyms and $\sim 4$ million participants, with an estimated net worth of \$4 billion USD (https://www.cnbc.com/2016/04/05/how-crossfit-rode-asingle-issue-to-world-fitness-domination.html).

A challenge for researchers is the intentionally varied nature of CF workouts (which, ironically, is one of the appeals for CF participation). This presents the challenge of quantifying training load because it is uncommon to repeat "Workouts of the Day" (WOD). Prior research has examined the metabolic responses to single, acute bouts of CF training. These studies have included named CF workouts, which are often used by CF practitioners as "benchmarks" to track 
progress. For example, two studies reported the intensity (91-97\% $\mathrm{HR}_{\mathrm{MAX}}$; 64-66\% $\left.\mathrm{VO}_{2} \max \right)$ and energy expenditure (261-318 kcal) for the "Cindy" workout (Kliszczewicz et al. 2014; Fernandez-Fernandez et al. 2015). It is important to note, however, that CF workouts often consist of a warm-up, a strength or skill exercise set, the WOD, a cool down, and possibly other exercises during the remainder of the day.

Data regarding energy balance responses in CF participants are severely limited. One published abstract, which estimated exercise energy expenditure (ExEE) and total energy expenditure (TEE), and relied on self-reported food records, reported that CF athletes had levels of energy availability (EA) of $\sim 33 \mathrm{kcals} / \mathrm{kg}$ FFM/d (Torres-McGehee et al. 2016). Objectively quantifying energy balance during a short-term period of CF training would provide novel information on how CF influences energy balance dynamics and physical activity patterns. This information could be useful for those individuals performing CF and looking to lose fat mass while gaining muscle mass. For example, work from Longland showed that when male athletes completed a combined high-intensity interval training and resistance exercise intervention $(6 \mathrm{~d} / \mathrm{wk})$ on a low calorie diet, individuals lost body mass while maintaining muscle mass (though both body mass loss and lean mass gain were greater in a high-protein compared to control group) (Longland et al. 2016). The results of that study, combined with data reporting CF participants consume lower levels of carbohydrates and protein than is recommended for athletes (Bonn et al. 2016; TorresMcGehee et al. 2016), may help to provide clearer information to promote optimal recovery, adaptation, and body composition changes in CF participants. 
Therefore, the purpose of the present study was to examine energy balance responses to one week of CF training. Energy expenditure, energy intake, energy availability, and changes in body composition were quantified over a 1-week period in active men and women.

\section{Methods}

\section{Participants}

Healthy men and women $(n=13$ and 8$)$, between the ages of $18-60$, were recruited from one CFaffiliated facility in the San Diego area (CrossFit Unsung, Poway, CA). Inclusion criteria included a minimum 3-month history of CF participation, no handicaps or physical disabilities preventing participation in moderate-vigorous physical activity (MVPA), no history of cardiometabolic diseases, not currently on medication influencing blood pressure or metabolism, and participating in at least $3 \mathrm{CF}$ sessions per week. Participants scaled workouts based on their ability and fitness levels; being able to perform the workout as prescribed (known as "Rx'ing") was not required for inclusion in the study. All participants completed informed consent, PARQ, and health history questionnaires before performing any testing.

\section{Experimental design}

This was a one-week observational study. Data were collected from October-December 2017 (a workout log over the study period, encompassing all possible gym workouts, is available upon request from the primary author). Participants were recruited on a rolling basis, 2-4 participants per week, over the study period. Participants reported to the Human Performance Laboratory (HPL) twice over an $\sim 8$-day span. During the study period, they were instructed to maintain their habitual exercise and dietary practices and were required to keep a written log of all 
exercise performed. CF workouts were recorded directly from the gym or through a mobile recording app (Beyond the White Board (BTWB), v. 6.0.2, BadPopcorn, Inc.). The primary investigators designed the study and received permission to recruit from the gym from the gym owner and head coach. The owner/coach reviewed, but did not assist in the design of, the study. All procedures were approved by the Human Subjects Institutional Review Board (ID: 11231211).

\section{Preliminary assessment}

Baseline assessments were conducted in the HPL between the hours of 6-10am. Participants arrived after an overnight fast ( $>10$ hours), with a 12-hour abstention from caffeine, alcohol, and MVPA. They were instructed to drink 12-16 oz of water before going to bed and upon waking to ensure proper hydration. Upon arrival, participants had their height and weight recorded. Body composition was assessed via air-displacement plethysmography (BOD POD, Life Measurement, Inc., Concord, CA, USA). Participants then completed an 8-minute sub-maximal step test for activity monitor calibration (see below). Finally, participants completed a $\mathrm{VO}_{2} \mathrm{max}$ test to exhaustion on a cycle ergometer (Velotron DynaFit Pro, Racermate, Inc., Seattle, WA, USA). Participants completed a ramp test starting at $60 \mathrm{~W}$ for 2 minutes, followed by an increase of $1 \mathrm{~W} \cdot 2 \operatorname{secs}^{-1}$ until volitional fatigue. Heart rate (H10, Polar Electro, Lake Success, NY, USA) and expired gases (ParvoMedics TrueOne 2400, Salt Lake City, UT, USA) were collected continuously and averaged at 15 -second intervals. Peak power output (PPO) was determined as the highest work value obtained during the test, while $\mathrm{VO}_{2}$ max was determined from averaging the final 30 seconds of the test and using established criteria (RER $\geq 1.10$, heart 
rate $\pm 10 \mathrm{~b} \cdot \mathrm{min}^{-1}$ of age-predicted maximum, and/or a plateau in $\dot{\mathrm{V}} \mathrm{O}_{2}<2.0 \mathrm{~mL} \cdot \mathrm{kg}^{-1} \cdot \mathrm{min}^{-1}$ ) (Robergs et al. 2010).

\section{Training period}

Participants were fitted an ActiHeart monitor (ActiHeart, Cambridge Neurotechnology Ltd., Cambridge, UK), affixed to the chest either with a chest band (Polar Electro, Lake Success, NY, USA) or standard electrodes (3M 2560 Red Dot, 3M Corporation, Minneapolis, MN, USA). They then completed a standardized 8 minute submaximal step test on a $21.5 \mathrm{~cm}$ step, beginning at $15 \mathrm{steps} / \mathrm{min}$ and ending at $33 \mathrm{steps} / \mathrm{min}$ (Brage et al. 2007). This protocol enables an individual heart rate-activity regression to be developed for each participant, which is more accurate than using a group-level calibration (Brage et al. 2007). After completing all laboratory testing, participants were provided a Bluetooth bio-impedance analysis scale (Bluetooth Smart Scale Model \#0375, Greater Goods Brand, St. Louis, MO, USA) and shown how to sync this to an app (WeightGurus, Greater Goods Brand, St. Louis, MO, USA) on their mobile device. They were instructed to weigh in every morning and to wear the ActiHeart as much as possible. During the training period, participants were required to attend at least $3 \mathrm{CF}$ classes and record any other exercise completed. All CF sessions were conducted under the supervision of the gym owner or another certified CF coach to ensure proper technique during exercise, along with warm-up, cool-down, and stretching activities.

\section{Follow-up assessment}

On their $8^{\text {th }}$ day, participants returned to the HPL at the same time of day as their baseline appointment $( \pm 1 \mathrm{~h})$, where body composition assessment was repeated. 


\section{Outcome measures}

The primary outcome in the current study was energy balance. Daily total energy expenditure (TEE) was calculated from the ActiHearts using branch-chained equation modelling of heart rate and activity data (Brage et al. 2007; Brage et al. 2015). Heart rate and activity were recorded at 1 min epochs. The ActiHeart has been validated against the gold standard criterion methods of indirect calorimetry and doubly-labelled water for the assessment of energy expenditure (Brage et al. 2007; Villars et al. 2012; Brage et al. 2015). The other component of energy balance, energy intake, was calculated based on TEE and changes in body composition. This method of calculating energy intake has been validated against the "intake-balance method" of doublylabelled water and dual x-ray absorptiometry (DXA) and utilized in a number of studies (Thomas et al. 2010; Thomas et al. 2012; Shook et al. 2015; Shook et al. 2018). The equation was:

$\mathrm{EI}=1020(\Delta \mathrm{FFM} / \Delta \mathrm{t})+9500(\Delta \mathrm{FM} / \Delta \mathrm{t})+\mathrm{TEE}$

Where $\triangle \mathrm{FFM}$ and $\triangle \mathrm{FM}$ represent change in each variable as measured by air displacement plethysmography; $\Delta \mathrm{t}$ represents the days between testing periods (i.e. 8 days); 1020 and 9500 represent the energy density (kcal) per kilogram of FFM and FM, respectively, based on established values (Thomas et al. 2010); and TEE represents total energy expenditure as measured by the ActiHearts. While some authors may argue that DXA is more accurate than the BodPod, we argue that the criterion for body composition should be a 4-compartment model (Muller et al. 2016), and internal data from our lab shows closer agreement of the BP and 4-C $(+1.1 \%)$ compared to DXA $(+4.6 \%)$ for the determination of body fat (in review). 
Resting metabolic rate (RMR) was calculated by the ActiHeart software using the equations of Schofield (Schofield 1985), and we averaged these values with those derived from the BodPod, which uses the equations of Nelson (Nelson et al. 1992). The thermic effect of food (TEF) was considered to account for $10 \%$ of TEE (Herrmann et al. 2015). Activity energy expenditure (AEE) was then calculated as:

$\mathrm{AEE}=\mathrm{TEE}-\mathrm{RMR}-\mathrm{TEF}$

Energy expenditure of CrossFit exercise sessions (CF EE) was determined by consulting the training logs and matching the start time and finish time with the recorded ActiHeart data, and subtracting from AEE. EA $\left(\mathrm{kcal} \cdot \mathrm{d}^{-1} \cdot \mathrm{kg} \mathrm{FFM}^{-1}\right)$ was calculated by subtracting AEE from calculated EI, and then dividing by the follow-up testing fat-free mass value. Physical activity level (PAL) was calculated by dividing TEE by RMR.

A final calculation was performed for energy compensation in response to CF training, as has been described previously (Riou et al. 2015). Energy compensation represents the over(increased energy intake and/or decreased NEPA) or under-compensation (decreased energy intake and/or increased NEPA) in response to an exercise intervention. It is calculated as:

Energy compensation $(\%)=(100 / \mathrm{ExEE}) *[(\Delta \mathrm{FM} * 9500)+(\Delta \mathrm{FFM} * 1020)]+100$ 
Where ExEE is the exercise energy expenditure of CF training; $\triangle \mathrm{FFM}$ and $\triangle \mathrm{FM}$ represent change in each variable as measured by air displacement plethysmography; and 1020 and 9500 represent the energy density (kcal) per kilogram of FFM and FM, respectively, based on established values (Thomas et al. 2010). A value of 100\% indicates that participants lost the amount of body weight predicted based on ExEE, a value of $0 \%$ indicates no change in body composition despite the increased ExEE, and a negative value indicates changes in body composition beyond what was predicted from ExEE (Rosenkilde et al. 2012; Riou et al. 2015; Schubert et al. 2017).

Time spent in varying levels of physical activity throughout the day was also assessed from ActiHeart data. This included time spent in sedentary $(\leq 1.5$ METs), light $(>1.5>3)$, moderate (3-6 METs), and vigorous (> 6 METs) activity during the day.

\section{Statistical analysis}

For purposes of wear time analysis from the ActiHearts, a cut-off value of $80 \%$ of the day (i.e. $0.8 * 1440$ minutes $=1152$ minutes required for analysis) was required for a day of data to be considered valid (Peacock et al. 2015; Nightingale et al. 2017). ActiHeart data were downloaded using a commercial software (ActiHeart v. 4.0.129, CamNTech, Inc., Cambridge, UK). Activity and heart rate data were then exported to Microsoft Excel at 1-minute intervals for integrity checks and analysis. All data were exported into a statistical package for analysis (SPSS v. 24, IBM Corp., Chicago, IL, USA). Means and standard deviations were calculated for descriptive statistics for the entire sample and by sex. Independent-samples t-test compared means by sex, with $95 \%$ confidence intervals $(95 \% \mathrm{CI})$ for the difference reported. A 2-way (time*sex) 
repeated measures analysis of covariance (ANCOVA), with week of data collection as a covariate, was conducted on TEE and AEE data. Where significant main effects or interactions were detected, post-hoc Bonferroni comparisons were conducted. Statistical significance was set as $\mathrm{p}<0.05$

\section{Results}

Characteristics of the study participants are available in Table 1. Attendance was not significantly different between men $(4.7 \pm 1.25$ sessions $)$ and women $(4.25 \pm 1.1$ sessions $)(p=$ 0.375 ; overall mean attendance $=4.5 \pm 1.08$ sessions). Eight of the thirteen men and 4 of the 8 women "Rx'd" at least $75 \%$ of their workouts. Median and range of days under observation were 8 (8-14 days). As would be anticipated, several significant sex differences were observed for baseline characteristics, i.e. men were taller, heavier, had a higher BMI, greater FFM, higher absolute deadlift 1-RM and deadlift:body weight ratio, and higher absolute $\mathrm{VO}_{2}$ max than women (Table 1).

\section{Weight and body composition}

For the whole sample, weight and body composition changes during the study period were -0.33 $\pm 1.23 \mathrm{~kg}(-0.27 \pm 1.35 \%)$, with a decrease of $-0.6 \pm 1.23 \mathrm{~kg}$ FM and increase of $0.25 \pm 1.42 \mathrm{~kg}$ FFM. These values suggest stable body weights during the study period, as these values fall within unpublished typical errors of measurement from our lab in 32 young men and women (1.3 $\mathrm{kg}$ for FFM and $1.16 \mathrm{~kg}$ for FM). Weight and fat mass changes were not different between men and women ( $\mathrm{p}=0.10$ and $\mathrm{p}=0.61$, respectively); however, men experienced a small loss in fatfree mass $(-0.23 \pm 1.4 \mathrm{~kg})$ compared to a gain in women $(1.02 \pm 1.15)(\mathrm{p}=0.047)$. 


\section{Energy balance components}

Components of energy balance are displayed in Table 2, with individual components of TEE displayed by participant in Figure 1. For all energy balance variables, men had higher values than women. However, these differences disappeared when adjusting for FFM (the exception being RMR, which was higher in women than men when adjusted for FFM). Goldberg values were utilized to examine the veracity of the calculated energy intake data, and indicated the data were plausible (Table 2). Energy availability was similar between men and women, and averaged $35 \mathrm{kcal} \cdot \mathrm{d}^{-1} \cdot \mathrm{kg} \mathrm{FFM}^{-1}$. Energy compensation was also not significantly different between men and women.

We observed no "weekend" effects when examining TEE and AEE responses over the study period. Specifically, there was no effect of time $(p=0.16)$ or time*week interaction $(p=0.155)$ for TEE. There was a main effect of $\operatorname{sex}(p=0.002)$ and a time* ${ }^{*}$ ex interaction $(p=0.017)$, whereby women had significantly lower unadjusted daily TEE than men (all comparisons $\mathrm{p}<$ 0.02). Similar patterns were observed for AEE, i.e. no effect of time $(p=0.30)$ or time*week interaction $(p=0.23)$, but a significant effect of $\operatorname{sex}(p=0.015)$ and sex*time interaction $(p=$ 0.035). Post-hoc comparisons revealed that AEE was lower in women on days $1,2,3$, and 7 ( $p<$ 0.04 for all) compared to men.

In terms of weekly CF EE, men expended significantly more calories than women $(3262 \pm 1090$ vs. $\left.1959 \pm 349 \mathrm{kcal} \cdot \mathrm{wk}^{-1}, \mathrm{p}=0.006\right)$, but when this was adjusted for FFM, the results were not different $\left(44.6 \pm 10.8\right.$ vs. $\left.40.6 \pm 7.6 \mathrm{kcal} \cdot \mathrm{wk}^{-1} \cdot \mathrm{kg} \mathrm{FFM}^{-1}, \mathrm{p}=0.61\right)$. 


\section{Physical activity time}

Physical activity data are shown in Table 3. Representative daily patterns of PA for morning and afternoon exercisers are shown in Figure 2. No differences in any of the PA domains existed between men and women. Participants spent $\sim 54 \%$ of their day sedentary. The average duration of CF sessions was $72 \pm 10$ minutes (range: 63-92). Importantly, MVPA was $\sim 170$ minutes, which suggests that in addition to $\mathrm{CF}$, participants completed an additional $\sim 100$ minutes of MVPA per day.

\section{Discussion}

The primary aim of the present study was to examine energy balance responses in $\mathrm{CF}$ participants during a one-week span. Results indicated that regular attendance at CF classes yielded energy expenditure well within ranges known to exert weight loss. Furthermore, despite the high-intensity nature of CF, participants completed an additional 100 minutes of MVPA per day, indicating that $\mathrm{CF}$ does not cause participants to compensate for the high intensity with decreased non-CF physical activity. Results also indicated that participants were generally in a small energy deficit, again suggesting there was no compensatory drive in energy intake in response to energy expenditure.

Exercise as a means of weight management has been utilized for decades, with mixed effects (Church et al. 2009; Donnelly et al. 2013). An optimal "dose" for weight management is still up for debate, but current recommendations for weight loss and weight maintenance are 150-300 mins $\cdot \mathrm{wk}^{-1}$ of at least moderate-intensity physical activity (Donnelly et al. 2009). For example, 
Donnelly and colleagues reported 2000 or $3000 \mathrm{kcal} \cdot \mathrm{wk}^{-1}$ of aerobic exercise resulted in significant (4-5 kg) weight loss in men and women, but without a difference between the volumes (Donnelly et al. 2013). Importantly, our novel results indicate that attending CF training for $\sim 315$ minutes $\cdot \mathrm{wk}^{-1}$ expended $\sim 2700 \mathrm{kcal} \cdot \mathrm{wk}^{-1}$. As these values are similar to current weight management guidelines, CF can be seen as a viable alternative compared to the traditional moderate-continuous aerobic exercise prescription for weight management. Furthermore, results from the literature generally support combined aerobic and resistance training (in accordance with existing guidelines) for simultaneously decreasing fat mass and increasing lean mass compared with either modality alone (Willis et al. 2012; Sparks et al. 2013; Earnest et al. 2014).

Prior research into $\mathrm{CF}$ has examined acute energy expenditure responses to various named or "benchmark" workouts. For example, the energy expenditure for the benchmark WOD "Cindy" has been reported to be between $13-16 \mathrm{kcal} \cdot \mathrm{min}^{-1}$ (Cindy is a 20 minute As-Many-Rounds-AsPossible (AMRAP) workout, consisting of 5 pull-ups, 10 push-ups, and 15 air squats) (Kliszczewicz et al. 2014; Fernandez-Fernandez et al. 2015). This is higher than the $\sim 8.4$ $\mathrm{kcal} \cdot \mathrm{min}^{-1}$ average we observed during CF training, but importantly, our sessions included warm-ups, pre-WOD exercises, the WOD, post-WOD activities, and cool-downs, which is a more accurate representation of daily CF training, at least in the gym utilized in the present study. Heart rate responses indicated participants spent $15.6 \pm 10.4 \%$ of their sessions in the light heart rate zone $\left(<50 \% \mathrm{HR}_{\mathrm{MAX}}\right), 45 \pm 9.4 \%$ in the moderate heart rate zone $(50-70 \%$ $\left.\mathrm{HR}_{\mathrm{MAX}}\right), 19.6 \pm 8 \%$ in the vigorous heart rate zone $\left(71-85 \% \mathrm{HR}_{\mathrm{MAX}}\right)$, and the final $19.8 \pm 8.5 \%$ of their sessions above $85 \% \mathrm{HR}_{\mathrm{MAX}}$. This is equivalent to $\sim 11.25, \sim 32.4, \sim 14.1$, and $\sim 14.25$ minutes in each zone, respectively. 
To our knowledge, only one other group has examined energy balance responses to CF training. In their first study, the authors examined energy balance using self-reported methods over 7 days. Interestingly, those authors' values were close to our own, which were obtained with objective measures, with values of $707 \pm 316 \mathrm{kcal} \cdot \mathrm{d}^{-1}$ reported for males and $428 \pm 185 \mathrm{kcal} \cdot \mathrm{d}^{-1}$ reported for females (694 and $461 \mathrm{kcal} \cdot \mathrm{session}^{-1}$ in the present study) (Torres-McGehee et al. 2016). However, it is unclear if their ExEE is merely from CF or if it included all exercise completed on a given day. In their second study, the authors reported an average workout duration of $\sim 38$ minutes and energy expenditure of $392 \mathrm{kcal}$ (Bonn et al. 2016). The difference in duration is likely due to differences in gyms - CF affiliates often have different programming or emphases (i.e. one gym may be more conditioning-focused while another may be more power/Olympic lifting focused); gyms may also be on different periodization or training cycles. Differences in location and environment could also contribute to differences in energy expenditure. The gym in the present study is located on level ground, in Southern California, and data was collected during late fall, when the weather is typically very mild. A gym located on a hill, or where data were collected in summer or winter, would have different EE results. Those authors also reported EA values of $34.6 \mathrm{kcal} \cdot \mathrm{d}^{-1} \cdot \mathrm{kg} \mathrm{FFM}^{-1}$ for males and $31.1 \mathrm{kcal} \cdot \mathrm{d}^{-1} \cdot \mathrm{kg} \mathrm{FFM}{ }^{-1}$ for females in one study and $27.4 \mathrm{kcal} \cdot \mathrm{d}^{-1} \cdot \mathrm{kg} \mathrm{FFM}^{-1}$ in another study (Bonn et al. 2016; TorresMcGehee et al. 2016). These are lower than what the American College of Sports Medicine considers to be optimal for health and performance in athletes, $40-45 \mathrm{kcal} \cdot \mathrm{d}^{-1} \cdot \mathrm{kg} \mathrm{FFM}^{-1}(\mathrm{Thomas}$ et al. 2016). Whether "athletes" and "active individuals" have similar or different energy needs is debatable, especially when one considers divergent goals (i.e. athletes may be focused on performance outcomes while the current participants may have been more interested in 
optimizing body composition and overall health and fitness). However, based on data from female athletes with the female athlete triad, ACSM defines insufficient EA as $<30 \mathrm{kcal} \cdot \mathrm{d}^{-1} \cdot \mathrm{kg}$ $\mathrm{FFM}^{-1}$ (Thomas et al. 2016). In the present study, 6 individuals fell below $30 \mathrm{kcal} \cdot \mathrm{d}^{-1} \cdot \mathrm{kg} \mathrm{FFM}^{-1}$ (5 males, 1 female). Whether these individuals were truly impacted by the "insufficient" EA, or were attempting to cut calories to manipulate body weight/composition cannot be known in the context of the present study; however, it would intuitively make sense that individuals attempting to create a negative energy deficit for weight loss would have lower levels of EA. Unfortunately, we cannot compare the incidence of EA levels $<30$ with prior studies because those studies only reported mean values (Bonn et al. 2016; Torres-McGehee et al. 2016).

\section{Limitations}

The primary limitation of the present study is the length of observation. Clinically meaningful changes in body composition would take a longer time to manifest. However, detecting changes in body composition was not the aim of the present study. Furthermore, nearly all exercise interventions that have assessed energy balance and physical activity responses utilize a 7-14 day assessment window (Willis et al. 2014; Shook et al. 2015; Shook et al. 2018). It is also worth noting that the work of Shook utilized DXA and Sensewear armbands instead of the BodPod and ActiHearts utilized in the present study (Shook et al. 2015; Shook et al. 2018). Hume and colleagues calculated energy balance values utilizing the BodPod and doubly-labeled water (Hume et al. 2016). While the BodPod may have slightly higher variability than the DXA, the ActiHeart has been shown to have strong agreement against both doubly-labelled water and indirect calorimetry (Brage et al. 2015; Chowdhury et al. 2017); in fact, the ActiHeart had better agreement with indirect calorimetry during lab-based activities when compared with the 
Sensewear (Chowdhury et al. 2017), thus it could be argued that any differences in methodology may "cancel out". Though we chose to utilize an objective measure of energy intake that required no participant burden, calculating EI from changes in TEE and body composition precluded us from obtaining other important dietary information such as macronutrient consumption. While our results suggest that total caloric intake was adequate in the present population, future research examining CF participants may wish to use weigh-and-measure food logs to get a better "snapshot" of macro- and micronutrient intake. An additional limitation is our results are not generalizable to all CF gyms due to the individual freedom each gym owner/coach is permitted in their programming. A final limitation is that our participants were generally active and motivated individuals. Many individuals completed additional CF and aerobic activities beyond the 60 minute class sessions; this is evidenced by the MVPA above and beyond the CF training. From a weight management standpoint, repeating this study in a sedentary and overweight/obese population would be of considerable interest and offer an opportunity to better examine compensatory responses to $\mathrm{CF}$ training.

\section{Conclusions}

Results of the present study suggest that on the basis of energy expended per training session and per week, CF can be a viable option for weight management. In trained participants, energy compensation does not occur; nor do these individuals compensate for the intensity of CF by reducing their activity the rest of the day. Future studies should examine long-term CF training (6+ weeks) in sedentary, untrained, overweight/obese participants to examine changes in body composition and energy balance. 
Acknowledgements: The authors thank the participants for their commitment and enthusiasm, and Gary Pennell (CrossFit Unsung, Poway, CA) for designing the training, supervising training, and providing safety.

Funding and Conflicts of Interest: No funding was received in support of this study. The authors have no conflicts of interest to disclose. 


\section{References}

2017. Level 1 Training Guide: CrossFit Training. Washington, D.C., USA: CrossFit, Inc. Bonn, E., Torres-McGehee, T.M., and Goins, J. 2016. Examination Of Recovery And Dietary Needs In Crossfit Athletes. Med. Sci. Sports Exerc. 48: 913-913. 10.1249/01.mss.0000487735.08379.90

Brage, S., Ekelund, U., Brage, N., Hennings, M.A., Froberg, K., Franks, P.W., et al. 2007. Hierarchy of individual calibration levels for heart rate and accelerometry to measure physical activity. J. Appl. Physiol. (1985), 103: 682-92. 10.1152/japplphysiol.00092.2006 Brage, S., Westgate, K., Franks, P.W., Stegle, O., Wright, A., Ekelund, U., et al. 2015. Estimation of Free-Living Energy Expenditure by Heart Rate and Movement Sensing: A Doubly-Labelled Water Study. PLoS One, 10: e0137206. 10.1371/journal.pone.0137206 Chowdhury, E.A., Western, M.J., Nightingale, T.E., Peacock, O.J., and Thompson, D. 2017. Assessment of laboratory and daily energy expenditure estimates from consumer multi-sensor physical activity monitors. PLoS One, 12: e0171720. 10.1371/journal.pone.0171720

Church, T.S., Martin, C.K., Thompson, A.M., Earnest, C.P., Mikus, C.R., and Blair, S.N. 2009. Changes in weight, waist circumference and compensatory responses with different doses of exercise among sedentary, overweight postmenopausal women. PLoS One, 4: e4515. 10.1371/journal.pone.0004515

Donnelly, J.E., Blair, S.N., Jakicic, J.M., Manore, M.M., Rankin, J.W., Smith, B.K., et al. 2009. American College of Sports Medicine Position Stand. Appropriate physical activity intervention strategies for weight loss and prevention of weight regain for adults. Med. Sci. Sports Exerc. 41: 459-71. 10.1249/MSS.0b013e3181949333

Donnelly, J.E., Honas, J.J., Smith, B.K., Mayo, M.S., Gibson, C.A., Sullivan, D.K., et al. 2013. Aerobic exercise alone results in clinically significant weight loss for men and women: midwest exercise trial 2. Obesity (Silver Spring), 21: E219-28. 10.1002/oby.20145

Drake, N., Smeed, J., Carper, M.J., and Crawford, D.A. 2017. Effects of short-term CrossFitTM Training: A Magnitude-Based Approach J. Exerc. Physiol. online, 20: 111-133.

Earnest, C.P., Johannsen, N.M., Swift, D.L., Gillison, F.B., Mikus, C.R., Lucia, A., et al. 2014. Aerobic and strength training in concomitant metabolic syndrome and type 2 diabetes. Med. Sci. Sports Exerc. 46: 1293-301. 10.1249/MSS.0000000000000242

Fernandez-Fernandez, J., Sabido-Solana, R., Moya, D., Sarabia, J.M., and Moya, M. 2015. Acute Physiological Responses during Crossfit (R) Workouts. Eur. J. Human Move. 35: 114-124. Gibala, M.J., and Hawley, J.A. 2017. Sprinting Toward Fitness. Cell Metab. 25: 988-990. 10.1016/j.cmet.2017.04.030

Herrmann, S.D., Willis, E.A., Honas, J.J., Lee, J., Washburn, R.A., and Donnelly, J.E. 2015. Energy intake, nonexercise physical activity, and weight loss in responders and nonresponders: The Midwest Exercise Trial 2. Obesity (Silver Spring), 23: 1539-49. 10.1002/oby.21073 Hume, D.J., Yokum, S., and Stice, E. 2016. Low energy intake plus low energy expenditure (low energy flux), not energy surfeit, predicts future body fat gain. Am. J. Clin. Nutr. 103: 1389-96. 10.3945/ajcn.115.127753

Kliszczewicz, B., Snarr, R.L., and Esco, M. 2014. Metabolic and cardiovascular response to the CrossFit workout "Cindy": A pilot study. J. Sport Human Perf. 2: 1-9.

10.12922/jshp.0038.2014

Longland, T.M., Oikawa, S.Y., Mitchell, C.J., Devries, M.C., and Phillips, S.M. 2016. Higher compared with lower dietary protein during an energy deficit combined with intense exercise 
promotes greater lean mass gain and fat mass loss: a randomized trial. Am. J. Clin. Nutr. 103: 738-46. 10.3945/ajen.115.119339

Muller, M.J., Braun, W., Pourhassan, M., Geisler, C., and Bosy-Westphal, A. 2016. Application of standards and models in body composition analysis. Proc. Nutr. Soc. 75: 181-7.

$10.1017 / \mathrm{S} 0029665115004206$

Nelson, K.M., Weinsier, R.L., Long, C.L., and Schutz, Y. 1992. Prediction of resting energy expenditure from fat-free mass and fat mass. Am. J. Clin. Nutr. 56: 848-56.

10.1093/ajcn/56.5.848

Nightingale, T.E., Williams, S., Thompson, D., and Bilzon, J.L.J. 2017. Energy balance components in persons with paraplegia: daily variation and appropriate measurement duration.

Int. J. Behav. Nutr. Phys. Act. 14: 132. 10.1186/s12966-017-0590-z

Peacock, O.J., Western, M.J., Batterham, A.M., Stathi, A., Standage, M., Tapp, A., et al. 2015. Multidimensional individualised Physical ACTivity (Mi-PACT)--a technology-enabled intervention to promote physical activity in primary care: study protocol for a randomised controlled trial. Trials, 16: 381. 10.1186/s13063-015-0892-x

Riou, M.E., Jomphe-Tremblay, S., Lamothe, G., Stacey, D., Szczotka, A., and Doucet, E. 2015. Predictors of Energy Compensation during Exercise Interventions: A Systematic Review.

Nutrients, 7: 3677-704. 10.3390/nu7053677

Robergs, R.A., Dwyer, D., and Astorino, T. 2010. Recommendations for improved data processing from expired gas analysis indirect calorimetry. Sports Med. 40: 95-111. 10.2165/11319670-000000000-00000

Rosenkilde, M., Auerbach, P., Reichkendler, M.H., Ploug, T., Stallknecht, B.M., and Sjodin, A. 2012. Body fat loss and compensatory mechanisms in response to different doses of aerobic exercise--a randomized controlled trial in overweight sedentary males. Am. J. Physiol. Regul. Integr. Comp. Physiol. 303: R571-9. 10.1152/ajpregu.00141.2012

Schofield, W.N. 1985. Predicting basal metabolic rate, new standards and review of previous work. Hum. Nutr. Clin. Nutr. 39 Suppl 1: 5-41.

Schubert, M.M., Palumbo, E., Seay, R.F., Spain, K.K., and Clarke, H.E. 2017. Energy compensation after sprint- and high-intensity interval training. PLoS One, 12: e0189590. 10.1371/journal.pone.0189590

Serafini, P., Hoffstetter, W., Mimms, H., Smith, M., Kliszczewicz, B., and Feito, Y. 2016. Body Composition And Strength Changes Following 16-weeks Of High-intensity Functional Training. Med. Sci. Sports Exerc. 48: 1001-1001. 10.1249/01.mss.0000488009.97613.c7

Shook, R.P., Hand, G.A., Drenowatz, C., Hebert, J.R., Paluch, A.E., Blundell, J.E., et al. 2015. Low levels of physical activity are associated with dysregulation of energy intake and fat mass gain over 1 year. Am. J. Clin. Nutr. 102: 1332-8. 10.3945/ajcn.115.115360 Shook, R.P., Hand, G.A., O'Connor, D.P., Thomas, D.M., Hurley, T.G., Hebert, J.R., et al. 2018. Energy Intake Derived from an Energy Balance Equation, Validated Activity Monitors, and Dual X-Ray Absorptiometry Can Provide Acceptable Caloric Intake Data among Young Adults. J. Nutr. 148: 490-496. 10.1093/jn/nxx029

Sobrero, G.L., Inman, C., Stone, W., Zagdsuren, B., Arnett, S.W., Shafer, M.A., et al. 2015. Crossfit Vs. Circuit-trained Individuals: Effects Of A Ten-week Training Program On Body Composition And Bone Mineral Density. Med. Sci. Sports Exerc. 47: 800-800. 10.1249/01.mss.0000478923.27125.12

Sparks, L.M., Johannsen, N.M., Church, T.S., Earnest, C.P., Moonen-Kornips, E., Moro, C., et al. 2013. Nine months of combined training improves ex vivo skeletal muscle metabolism in 
individuals with type 2 diabetes. J. Clin. Endocrinol. Metab. 98: 1694-702. 10.1210/jc.20123874

Thomas, D.M., Bouchard, C., Church, T., Slentz, C., Kraus, W.E., Redman, L.M., et al. 2012. Why do individuals not lose more weight from an exercise intervention at a defined dose? An energy balance analysis. Obes. Rev. 13: 835-47. 10.1111/j.1467-789X.2012.01012.x

Thomas, D.M., Schoeller, D.A., Redman, L.A., Martin, C.K., Levine, J.A., and Heymsfield, S.B. 2010. A computational model to determine energy intake during weight loss. Am. J. Clin. Nutr. 92: 1326-31. 10.3945/ajcn.2010.29687

Thomas, D.T., Erdman, K.A., and Burke, L.M. 2016. American College of Sports Medicine Joint Position Statement. Nutrition and Athletic Performance. Med. Sci. Sports Exerc. 48: 543-68. 10.1249/MSS.0000000000000852

Torres-McGehee, T.M., Niemela, C., Goins, J., and Emerson, D.M. 2016. Examination of Eating Disorder Risk, Dietary Intake and Body Composition in CrossFit Athletes. Med. Sci. Sports Exerc. 48: 1025-1025. 10.1249/01.mss.0000488084.88203.96

Troiano, R.P., Berrigan, D., Dodd, K.W., Masse, L.C., Tilert, T., and McDowell, M. 2008. Physical activity in the United States measured by accelerometer. Med. Sci. Sports Exerc. 40: 181-8. 10.1249/mss.0b013e31815a51b3

Villars, C., Bergouignan, A., Dugas, J., Antoun, E., Schoeller, D.A., Roth, H., et al. 2012. Validity of combining heart rate and uniaxial acceleration to measure free-living physical activity energy expenditure in young men. J. Appl. Physiol. (1985), 113: 1763-71.

10.1152/japplphysiol.01413.2011

Willis, E.A., Herrmann, S.D., Honas, J.J., Lee, J., Donnelly, J.E., and Washburn, R.A. 2014. Nonexercise energy expenditure and physical activity in the Midwest Exercise Trial 2. Med. Sci. Sports Exerc. 46: 2286-94. 10.1249/MSS.0000000000000354

Willis, L.H., Slentz, C.A., Bateman, L.A., Shields, A.T., Piner, L.W., Bales, C.W., et al. 2012. Effects of aerobic and/or resistance training on body mass and fat mass in overweight or obese adults. J. Appl. Physiol. (1985), 113: 1831-7. 10.1152/japplphysiol.01370.2011 Zagdsuren, B., Evans, G.S., Inman, C., Stone, W., Arnett, S., Schafer, M., et al. 2015. Crossfit Vs. Circuit-training: Effects Of A Ten-week Training Program On Aerobic, Anaerobic And Flexibility Indicators. Med. Sci. Sports Exerc. 47: 801-801.

10.1249/01.mss.0000478926.16823.b9 
Table 1: Characteristics of study participants

\begin{tabular}{|c|c|c|c|c|c|}
\hline & $\operatorname{Men}(n=13)$ & Women $(\mathrm{n}=8)$ & All $(n=21)$ & P-value* & $95 \% \mathrm{CI}^{* *}$ \\
\hline Age (yrs) & $42 \pm 8$ & $45 \pm 10$ & $43.5 \pm 8.4$ & 0.44 & $-11.0,5.0$ \\
\hline CF participation (yrs) & $3.0 \pm 2.7$ & $1.8 \pm 2.0$ & $2.6 \pm 2.4$ & 0.23 & $-0.94,3.6$ \\
\hline Height (m) & $1.77 \pm 0.10$ & $1.64 \pm 0.10$ & $1.72 \pm 0.11$ & 0.002 & $0.06,0.22$ \\
\hline Weight (kg) & $93.3 \pm 19.2$ & $66.75 \pm 7.16$ & $83.2 \pm 20.3$ & 0.001 & $11.67,41.49$ \\
\hline $\begin{array}{l}\text { Body Mass Index } \\
\left(\mathrm{kg} \cdot \mathrm{m}^{-2}\right)\end{array}$ & $29.5 \pm 5.1$ & $25.0 \pm 3.1$ & $27.8 \pm 4.9$ & 0.038 & $0.29,8.65$ \\
\hline Body Fat (\%) & $21.3 \pm 8.0$ & $28.2 \pm 8.9$ & $23.9 \pm 8.8$ & 0.084 & $-14.68,1.00$ \\
\hline Fat Mass $(\mathrm{kg})$ & $20.6 \pm 10.7$ & $19.05 \pm 7.07$ & $20.03 \pm 9.3$ & 0.71 & $-7.32,10.53$ \\
\hline Fat-free Mass (kg) & $72.7 \pm 11.9$ & $47.7 \pm 5.5$ & $63.17 \pm 15.8$ & $<0.0001$ & $15.56,34.41$ \\
\hline 1-RM Deadlift (kgs) & $155 \pm 34$ & $82 \pm 12$ & $127 \pm 46$ & $<0.0001$ & $47.4,99.77$ \\
\hline $\begin{array}{l}\text { 1-RM Deadlift } \\
\left(\mathrm{kgs} \cdot \mathrm{BW}^{-1}\right)\end{array}$ & $1.71 \pm 0.43$ & $1.24 \pm 0.22$ & $1.53 \pm 0.43$ & 0.004 & $0.17,0.77$ \\
\hline $\mathrm{VO}_{2} \max \left(\mathrm{L} \cdot \mathrm{min}^{-1}\right)$ & $3.6 \pm 0.7$ & $2.3 \pm 0.5$ & $3.1 \pm 0.9$ & 0.0003 & $0.66,1.83$ \\
\hline $\begin{array}{l}\mathrm{VO}_{2} \max (\mathrm{mL} \cdot \mathrm{kg} \\
\left.\mathrm{FFM}^{-1} \cdot \mathrm{min}^{-1}\right)\end{array}$ & $49.2 \pm 6.3$ & $48.4 \pm 8.0$ & $48.9 \pm 6.8$ & 0.81 & $-5.78,7.31$ \\
\hline $\begin{array}{l}\text { Peak Power Output } \\
\text { (Watts) }\end{array}$ & $317 \pm 50$ & $224 \pm 55$ & $282 \pm 69$ & 0.001 & $45.34,142.43$ \\
\hline
\end{tabular}

Data are means $\pm \mathrm{SD}$. ${ }^{*} \mathrm{P}$-values are for independent-samples $t$-tests between men and women. $* * 95 \%$ confidence interval for difference between means. Significant values are bolded. 
Table 2: Components of energy balance (8-day averages)

\begin{tabular}{|c|c|c|c|c|c|}
\hline & $\operatorname{Men}(\mathrm{n}=13)$ & Women $(\mathrm{n}=8)$ & All $(n=21)$ & P-value* & $95 \% \mathrm{CI}^{* *}$ \\
\hline $\begin{array}{l}\text { Resting metabolic rate } \\
\left(\mathrm{kcal} \cdot \mathrm{d}^{-1}\right)\end{array}$ & $1963 \pm 250$ & $1369 \pm 124$ & $1737 \pm 361$ & $<0.0001$ & 394,793 \\
\hline $\begin{array}{l}\text { Resting metabolic rate } \\
\left(\mathrm{kcal}^{-d^{-1}} \cdot \mathrm{kg} \mathrm{FFM}^{-1}\right)\end{array}$ & $27.2 \pm 1.6$ & $28.8 \pm 1.4$ & $27.8 \pm 1.7$ & 0.027 & $-3.06,-0.20$ \\
\hline $\begin{array}{l}\text { Total energy expenditure } \\
\left(\mathrm{kcal} \cdot \mathrm{d}^{-1}\right)\end{array}$ & $4143 \pm 751$ & $2913 \pm 230$ & $3674 \pm 855$ & $<0.0001$ & 754,1705 \\
\hline $\begin{array}{l}\text { Total energy expenditure } \\
\left(\mathrm{kcal} \cdot \mathrm{d}^{-1} \cdot \mathrm{kg} \mathrm{FFM}^{-1}\right)\end{array}$ & $57.6 \pm 9.5$ & $60.2 \pm 4.4$ & $58.6 \pm 7.9$ & 0.477 & $-10.13,4.91$ \\
\hline $\begin{array}{l}\text { Activity energy } \\
\text { expenditure }\left(\mathrm{kcal} \cdot \mathrm{d}^{-1}\right)\end{array}$ & $1753 \pm 558$ & $1229 \pm 189$ & $1553 \pm 517$ & 0.007 & 167,881 \\
\hline $\begin{array}{l}\text { Activity energy } \\
\text { expenditure }\left(\mathrm{kcal} \cdot \mathrm{d}^{-1} \cdot \mathrm{kg}\right. \\
\left.\mathrm{FFM}^{-1}\right)\end{array}$ & $24.4 \pm 7.8$ & $25.5 \pm 4.3$ & $24.8 \pm 6.7$ & 0.72 & $-7.44,5.24$ \\
\hline $\begin{array}{l}\text { CrossFit energy } \\
\text { expenditure } \\
\left(\mathrm{kcal} \cdot \mathrm{session}^{-1}\right)\end{array}$ & $694 \pm 232$ & $461 \pm 82$ & $605 \pm 219$ & 0.004 & 83,382 \\
\hline $\begin{array}{l}\text { CrossFit energy } \\
\text { expenditure } \\
\left(\mathrm{kcal} \cdot \mathrm{session}^{-1} \cdot \mathrm{kg} \mathrm{FFM}^{-1}\right)\end{array}$ & $9.49 \pm 2.39$ & $9.55 \pm 1.79$ & $9.51 \pm 2.13$ & 0.95 & $-2.12,1.99$ \\
\hline $\begin{array}{l}\text { Calculated energy intake } \\
\left(\mathrm{kcal} \cdot \mathrm{d}^{-1}\right)\end{array}$ & $3705 \pm 1387$ & $2294 \pm 948$ & $3167 \pm 1401$ & 0.021 & 242,2581 \\
\hline 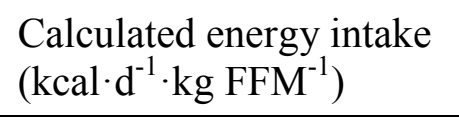 & $50.3 \pm 14.4$ & $47.9 \pm 20.3$ & $49.4 \pm 16.5$ & 0.754 & $-13.43,18.24$ \\
\hline $\begin{array}{l}\text { Goldberg cut-off } \\
\left(\mathrm{EI}^{-} \mathrm{RMR}^{-1}\right)\end{array}$ & $1.86 \pm 0.57$ & $1.70 \pm 0.75$ & $1.80 \pm 0.63$ & 0.587 & $-0.45,0.77$ \\
\hline $\begin{array}{l}\text { Energy availability } \\
\left(\mathrm{kcal}^{-\mathrm{d}^{-1}} \cdot \mathrm{kg} \mathrm{FFM}^{-1}\right)\end{array}$ & $34.08 \pm 8.81$ & $36.75 \pm 7.44$ & $35.1 \pm 8.23$ & 0.484 & $-10.51,5.16$ \\
\hline $\begin{array}{l}\text { Physical Activity Level } \\
\left(\mathrm{PAL}, \mathrm{TEE} \cdot \mathrm{RMR}^{-1}\right)\end{array}$ & $2.11 \pm 0.28$ & $2.13 \pm 0.16$ & $2.12 \pm 0.24$ & 0.828 & $-0.23,0.18$ \\
\hline $\begin{array}{l}\text { Energy compensation } \\
(\%)\end{array}$ & $-58 \pm 328$ & $-302 \pm 556$ & $-151 \pm 433$ & 0.219 & $-158,645$ \\
\hline
\end{tabular}

Data are means $\pm \mathrm{SD}$. *P-values are for independent-samples $t$-tests between men and women. $* * 95 \%$ confidence interval for difference between means. Significant values are bolded. 
Table 3: Daily Physical Activity

\begin{tabular}{|l|c|c|c|c|c|}
\hline $\begin{array}{l}\text { Physical activity domain } \\
\left(\text { minutes } \cdot \mathrm{d}^{-1}\right)\end{array}$ & Men $(\mathrm{n}=13)$ & Women $(\mathrm{n}=8)$ & All $(\mathrm{n}=21)$ & P-value* & $95 \% \mathrm{CI}^{* *}$ \\
\hline Sedentary time $(\leq 1.5$ METs $)$ & $795 \pm 239$ & $737 \pm 195$ & $773 \pm 220$ & 0.566 & $-152,269$ \\
\hline $\begin{array}{l}\text { Light physical activity }(>1.5 \\
>3 \text { METs })\end{array}$ & $473 \pm 230$ & $539 \pm 182$ & $498 \pm 211$ & 0.499 & $-267,135$ \\
\hline $\begin{array}{l}\text { Moderate physical activity } \\
(3-6 \text { METs) }\end{array}$ & $144 \pm 49$ & $139 \pm 39$ & $142 \pm 44$ & 0.809 & $-38,48$ \\
\hline $\begin{array}{l}\text { Vigorous physical activity }(> \\
6 \text { METs })\end{array}$ & $28 \pm 8$ & $25 \pm 13$ & $27 \pm 10$ & 0.583 & $-7,12$ \\
\hline $\begin{array}{l}\text { Moderate-Vigorous physical } \\
\text { activity }\end{array}$ & $172 \pm 50$ & $164 \pm 50$ & $169 \pm 49$ & 0.744 & $-40,55$ \\
\hline
\end{tabular}

Data are means \pm SD. METs, metabolic equivalent of tasks. *P-values are for independentsamples $t$-tests between men and women. $* * 95 \%$ confidence interval for difference between means. Significant values are bolded.

Figure captions:

Figure 1: Components of daily energy balance in individual participants by ascending TEE. Top panel, raw data. Bottom panel, adjusted for FFM. Checkered box, RMR; filled black box, TEF; filled white box, AEE; filled grey box, CrossFit EE.

Figure 2: Representative minute by minute daily energy expenditure for morning (top panels) and afternoon (bottom panels) exercisers. Dotted lines represent individual RMR. 

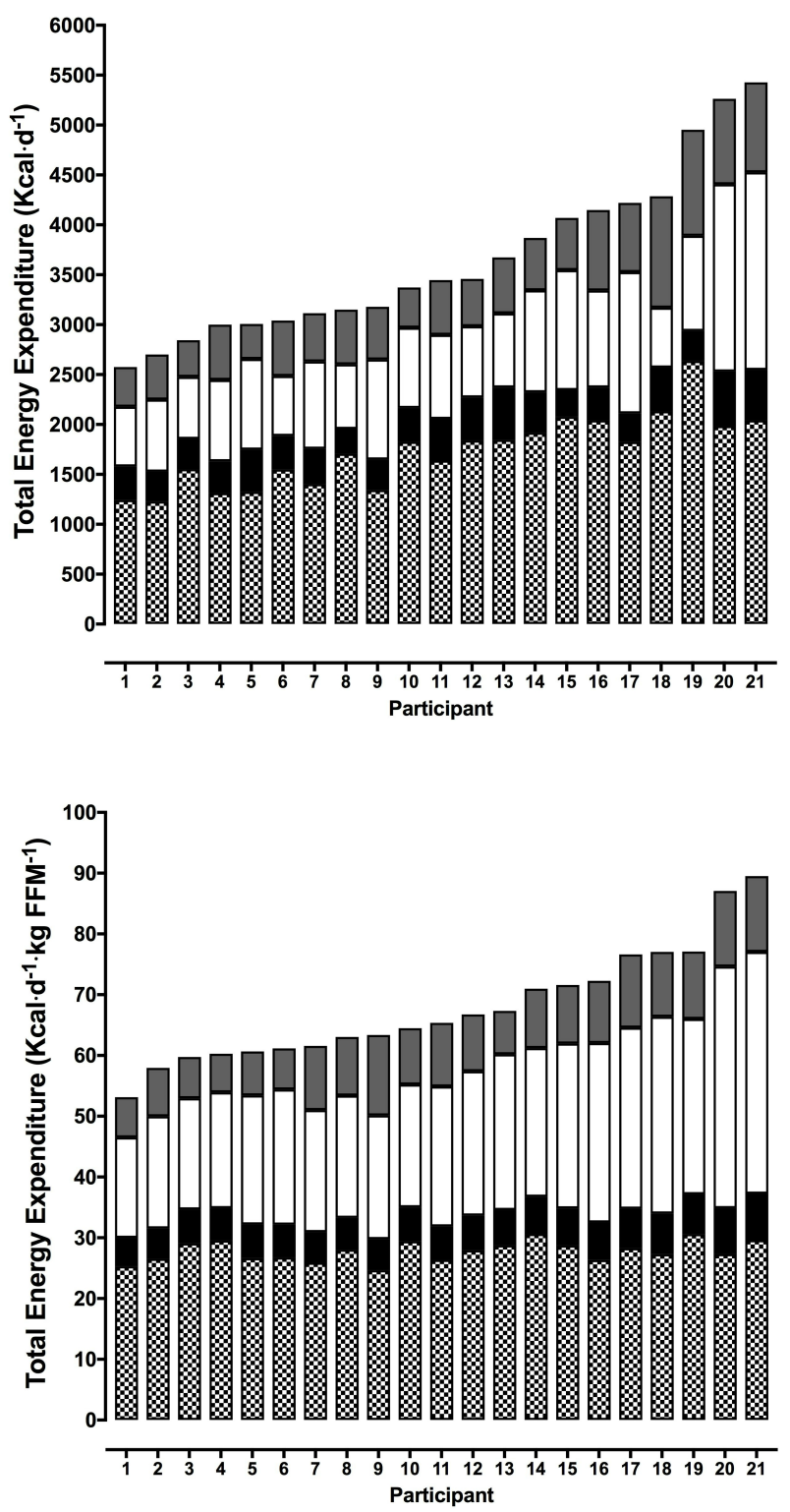

Figure 1: Components of daily energy balance in individual participants by ascending TEE. Top panel, raw data. Bottom panel, adjusted for FFM. Checkered box, RMR; filled black box, TEF; filled white box, AEE; filled grey box, CrossFit EE.

$228 \times 414 \mathrm{~mm}(300 \times 300$ DPI $)$ 

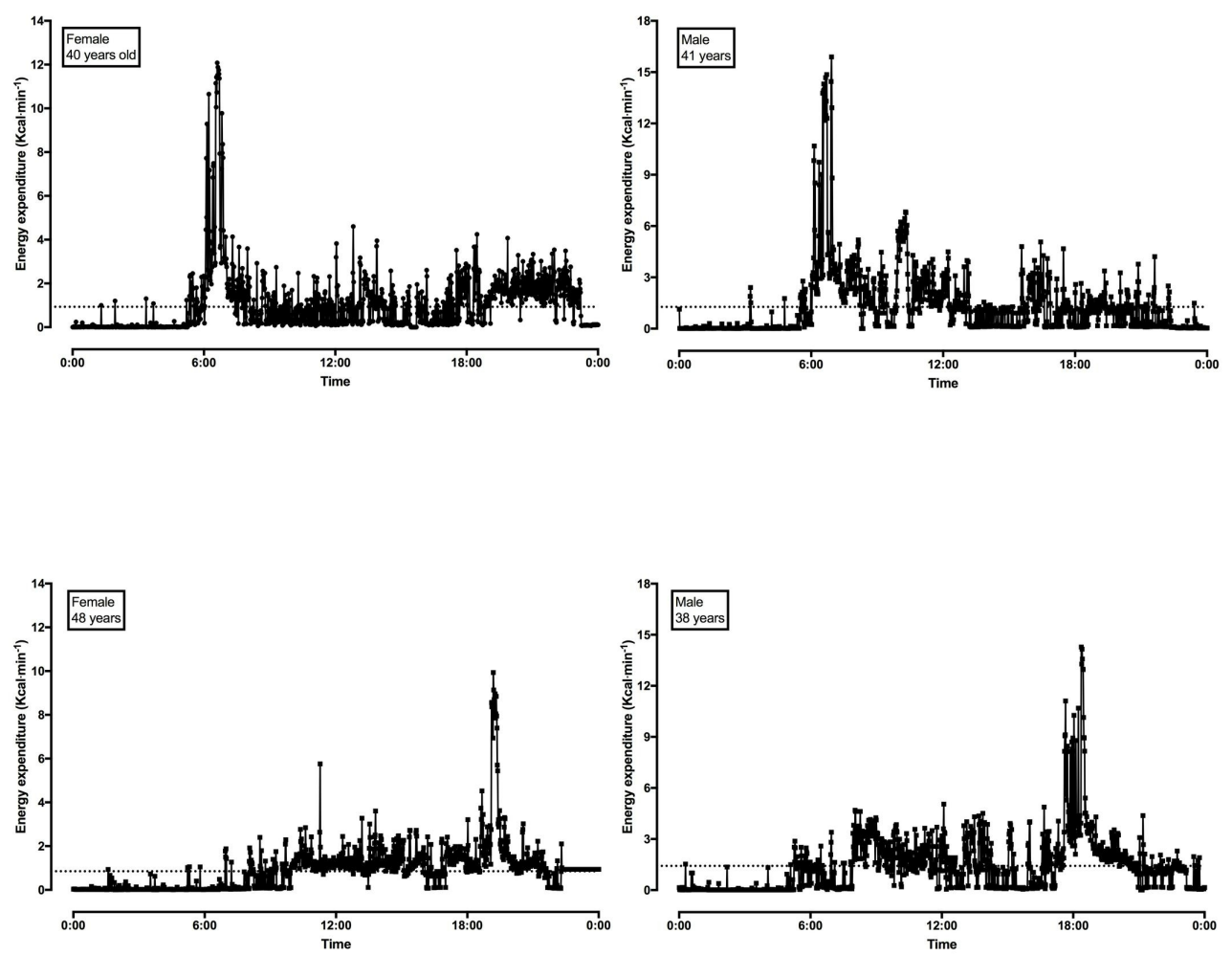

Figure 2: Representative minute by minute daily energy expenditure for morning (top panels) and afternoon (bottom panels) exercisers. Dotted lines represent individual RMR.

$184 \times 143 \mathrm{~mm}(300 \times 300 \mathrm{DPI})$ 